\title{
Early Inhaled Nitric Oxide Improves Oxidative Balance in Very Preterm Infants
}

\author{
ISABELLE HAMON, JEANNE FRESSON, MARIE-BENEDICTE NICOLAS, \\ MARIE-CHRISTINE BUCHWEILLER, PATRICIA FRANCK, AND JEAN-MICHEL HASCOET
}

Neonatology Division [I.H., M.-C.B., J.-M.H.], Maternite Regionale Universitaire de Nancy, Nancy 54042,

France; Statistics Department [J.F.], Maternite Regionale Universitaire de Nancy, Nancy 54042, France; and Laboratoires de Biochimie du CHU de Nancy [M.-B.N., P.F.], Nancy 54000, France

\begin{tabular}{|c|c|}
\hline \multicolumn{2}{|c|}{ ABSTRACT } \\
\hline $\begin{array}{l}\text { Inhaled nitric oxide (iNO) improves oxygenation in prema- } \\
\text { ture infants, but concern has been raised about its potential } \\
\text { oxidative toxicity. We designed this study to assess the oxidative } \\
\text { balance in premature infants who were exposed to low dose iNO } \\
\text { and the relationship with their clinical outcome on day } 28 \text { of life. } \\
\text { A total of } 274 \text { infants who were }<32 \text { wk gestation were random- } \\
\text { ized at birth to receive } 5 \text { ppm of iNO if they presented with } \\
\text { hypoxemic respiratory failure. Nonhypoxemic infants were stud- } \\
\text { ied as the reference group. Blood samples were withdrawn } 24 \text { h } \\
\text { apart, within the first } 4 \text { d of life, to assess malondialdehyde } \\
\text { (MDA) concentration as oxidative stress marker and total plas- } \\
\text { matic glutathione (GSH), intraerythrocyte GSH peroxidase, and } \\
\text { GSH reductase activities as antioxidant defenses. After } 24 \text { h, the } \\
\text { rise in MDA was blunted in the iNO group compared with } \\
\text { controls and was close to the reference infants. Conversely, GSH } \\
\text { was more stable in the iNO group, when there was no difference } \\
\text { for the GSH peroxidase and GSH reductase activities. On day } 28 \text {, } \\
\text { Oxygen dependence was linked with a higher increase in MDA } \\
\text { as was the risk for death, whereas intraventricular hemorrhage } \\
\text { was associated with a higher initial drop in GSH. Early low-dose }\end{array}$ & 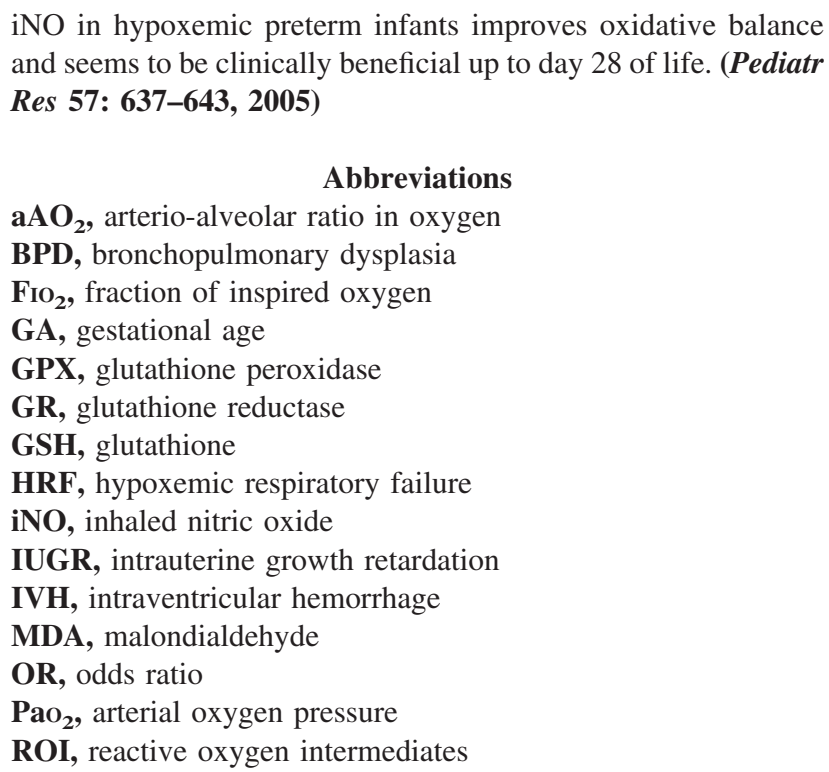 \\
\hline
\end{tabular}

Since 1992, several randomized trials have shown that inhaled nitric oxide (iNO) significantly improved oxygenation in term or near-term infants, with a significant reduction in the use of extracorporeal membrane oxygenation (1-6). In 1997, Skimming et al. (7) were the first to report a positive response of 23 premature infants with respiratory distress syndrome to low-dose iNO (5 ppm). Since then, a few clinical trials involving a small number of premature infants have shown that the initial improvement in oxygenation seemed to be transient (8-10) because no improvement in mortality or in morbidity had been demonstrated (11). However, most of these studies

Received May 20, 2004; accepted September 27, 2004.

Correspondence: Isabelle Hamon, M.D., Reanimation Neonatale, Maternite Regionale Universitaire de Nancy, 10 rue du Dr Heydenreich, 54042 Nancy Cedex, France; e-mail: i.hamon@maternite.chu-nancy.fr.

This work was supported by the Maternite Regionale Universitaire de Nancy.

DOI: 10.1203/01.PDR.0000156507.03879.19 were considering iNO therapy in premature infants who had severe hypoxemic respiratory failure or refractory hypoxemia $(8,10,11)$ or were at an advanced stage of respiratory insufficiency (12). Most of them used a high dosage of iNO (10-20 ppm).

Finally, concerns have been raised about specific side effects of this new molecule that could worsen long-term outcome after an initial improvement in this high-risk population (1315). Besides the risk for increased brain hemorrhage as a result of a prolonged bleeding time (16), neonatologists remain cautious in the use of this treatment because NO behaves as a "chameleon" molecule for the oxidative balance. Endogenous $\mathrm{NO}$ is incriminated in the cascade leading to cerebral lesions in perinatal experimental models of hypoxo-ischemic injuries (17). In addition, iNO may interact with oxygen to form nitrogen dioxide and peroxynitrites, which would enhance pulmonary toxicity. This is a main concern when dealing with 
premature infants, who already are unable to face oxidant stress $(18,19)$. However, at low dosage and in experimental models, NO is described as antioxidant at the lung level, able to counteract oxidative stress and enhance surfactant function $(20,21)$. Low doses of iNO also seem to improve oxygenation in premature infants with chronic lung disease $(11,12)$ without alteration of their inflammatory markers. Thus, a policy of treatment aiming to get a beneficial and sustained protective effect of iNO in preterm infants should take into account their fragile oxidative balance. Therefore, we designed this study, as part of a large multicenter trial studying the safety and efficacy of early low-dose iNO (22), to assess the oxidative balance of very premature infants according to their respiratory status and the effect of iNO on this balance.

\section{METHODS}

Study population. This prospective, randomized, controlled trial was conducted in an academic level III neonatal unit and approved by the "Comite Consultatif de Protection des Personnes soumises à la Recherche Biomedicale" and by our Institutional Review Board. Inclusion criteria were gestational age (GA) $<32 \mathrm{wk}$ at birth and $<48 \mathrm{~h}$ of life, with written informed consent of the parents. Exclusion criteria were initial refractory hypoxemia, thrombocytopenia $<50,000 / \mathrm{mm}^{3}$, or the presence of major fetal abnormality.

Study design. Randomization was stratified by GA $(<28$ wk and $28-31 \mathrm{wk}$ $\mathrm{GA}$ ) and kept blind until $6 \mathrm{~h}$ of age with optimal care performed according to standardized written protocols. Subsequently, up to $48 \mathrm{~h}$ after birth, when the infants presented with hypoxemic respiratory failure (HRF) defined as the need for mechanical ventilation with a fraction of inspired oxygen $\left(\mathrm{FIO}_{2}\right)>0.4$ and had an arterio-alveolar $\mathrm{O}_{2}$ ratio $\left[\mathrm{aAO}_{2} ; \mathrm{aAO}_{2}=\right.$ arterial oxygen pressure $\left(\mathrm{PaO}_{2}\right) / 713 \times \mathrm{FIO}_{2}-$ arterial partial pressure of $\left.\mathrm{CO}_{2}\right]<0.22$ but no refractory hypoxemia (defined as $\mathrm{PO}_{2}<50$ and $\mathrm{PCO}_{2}<50 \mathrm{~mm} \mathrm{Hg}$ for $\mathrm{FIO}_{2}=1.0$ ), the allocation was disclosed as "control" or "iNO" group. For both HRF groups, one blood sample $(1 \mathrm{~mL})$ was withdrawn at the time of randomization $\left(\mathrm{T}_{1}\right)$ through a central line, and a second sample $\left(\mathrm{T}_{2}\right)$ was drawn $24 \mathrm{~h}$ later for biologic analysis. iNO was delivered from a certified 225-ppm cylinder (Air Liquide Sante International, Paris, France) with a compact unit including a pressure regulator and a low-flow meter $(0.1-1.5 \mathrm{~L} / \mathrm{min})$. NO and nitrogen dioxide were continuously monitored at the T-piece with electrochemical cells (Polytron, DrägerAG, Lübeck, Germany). A dose of $5 \mathrm{ppm}$ of iNO was first used for $1 \mathrm{~h}$ in the iNO group, and then subsequent dosage was determined according to $\mathrm{aAO}_{2}$ response. As soon as the response was positive (defined as an $\mathrm{aAO}_{2}$ increase $>0.22$ ), iNO was decreased to $2 \mathrm{ppm}$ for $2 \mathrm{~h}$ and then weaned according to blood gas examination; when the response was intermediate $\left(\mathrm{aAO}_{2}\right.$ remaining $<0.22$ but increasing by at least $\left.25 \%\right)$, iNO was left at $5 \mathrm{ppm}$ for $2 \mathrm{~h}$ and the response was re-evaluated every $2 \mathrm{~h}$ thereafter. Finally, when the infants showed no response, iNO was increased up to $10 \mathrm{ppm}$ for $2 \mathrm{~h}$ and then re-evaluated. In case of treatment failure, iNO was weaned after $4 \mathrm{~h}$. If during these $48 \mathrm{~h}$ the infants did not present with HRF ("reference group"), then randomization was kept blind until analysis, usual optimal care was performed, and two blood samples $\left(\mathrm{T}_{1}\right.$ and $\left.\mathrm{T}_{2}\right)$ were drawn $24 \mathrm{~h}$ apart during the first $72 \mathrm{~h}$ of life.

Biologic analysis. All blood samples were processed immediately and frozen at $-20^{\circ} \mathrm{C}$ and $-80^{\circ} \mathrm{C}$ until final biochemical analysis, blinded for the allocation group.

Malondialdehyde (MDA) plasmatic concentration, the marker of oxidative stress, was assessed by colorimetric method (Kit MDA Sobioda). This measurement was based on the reaction of MDA with two molecules of thiobarbituric acid, after heating at $95^{\circ} \mathrm{C}$, to form a pink fluorescent complex at 553 $\mathrm{nm}(23,24)$. Results were expressed in $\mathrm{nmol} / \mathrm{g}$ of serum protein.

Total plasmatic glutathione (GSH) was assessed by enzymatic assay by a method based on the spectrophotometric monitoring of GSH-mediated reduction of 5,5'-dithio-bis (2-nitrobenzoic acid) at $412 \mathrm{~nm}$ (25). Plasmatic GSH, chosen as antioxidant substrate, was expressed in nmol/L.

Intraerythrocyte glutathione peroxidase (GPX) activity was determined by enzymatic assay following the oxidation of reduced GSH, in the presence of glutathione reductase (GR), by measuring the decrease of NADPH concentration at $340 \mathrm{~nm}$. Results were expressed in $\mu \mathrm{mol}$ of oxidized NADPH per min $/ \mathrm{g}$ $\mathrm{Hb}(26)$.

Intraerythrocyte GR activity acts as a GSH regenerator by catalyzing the reduction of GSH disulfite in the presence of NADPH (27), which is oxidized to $\mathrm{NADP}^{+}$. The decrease in absorbance at $340 \mathrm{~nm}$ was measured (Kit RANDOX), and results were expressed in $\mu \mathrm{mol} \cdot \mathrm{min}^{-1} \cdot \mathrm{g} \mathrm{Hb}^{-1}$.

Data collection and clinical outcome measures. History of toxemia, gestational diabetes, premature rupture of membranes, chorioamnionitis, maternal-fetal infection, and the use of antenatal steroids was recorded carefully following a standardized review of the maternal medical records. We prospectively recorded placental abruption; mode of delivery; newborn characteristics; episodes of illness; all events that occurred at birth and within the first $28 \mathrm{~d}$ of life, such as the incidence and severity of intraventricular hemorrhage (IVH) and periventricular leukomalacia thanks to weekly head ultrasound examination; and the prevalence of oxygen dependence on day 28. The primary measure of outcome of the clinical trial was defined as survival on day 28 without any respiratory support, oxygen supplementation, or IVH greater than grade I (28).

Statistical analysis. Categorical variables were compared among the three groups by either $\chi^{2}$ or Fischer exact test. Continuous variables were compared by two-way ANOVA for one or two parameters and completed by Tukey pair-wise comparisons test when global test was positive. We considered $p<$ 0.05 as significant.

The relationship between MDA or GSH and the clinical outcome on day 28 was studied by ANOVA when normality of the data was achieved. Otherwise, we used Kruskal-Wallis test to measure differences of a single variable across two or more independent groups of cases. When linearity of the data was achieved, MDA and GSH were categorized using $5 \mathrm{nmol} / \mathrm{g}$ protein and 0.1 -nmol/L intervals, respectively, and odds ratio (OR) were calculated. Data are presented as mean \pm SEM or median (25th-75th quartiles). Statistical analysis was performed with SAS 8.2 software (SAS Institute, Cary, NC).

\section{RESULTS}

Population. From July 1999 to February 2001, 274 premature infants received care in our unit. After exclusion for parental refusal or exclusion criteria $(n=22)$, lack of biologic sampling $(n=6)$, or protocol violation $(n=6), 240$ infants were studied and distributed within three subgroups: reference $(n=164)$, HRF-control $(n=39)$ and HRF-iNO $(n=37$; Fig. 1). Demographic and baseline characteristics before randomization are presented in Table 1 . Mean GA was significantly higher in the reference group in comparison with both HRF groups. There was no statistical difference among the three groups for birth weight, sex distribution, incidence of maternal toxemia, chorioamnionitis, severe intrauterine growth retardation, or the incidence of cesarean section. We noticed a higher rate of antenatal steroid use for the reference group versus the

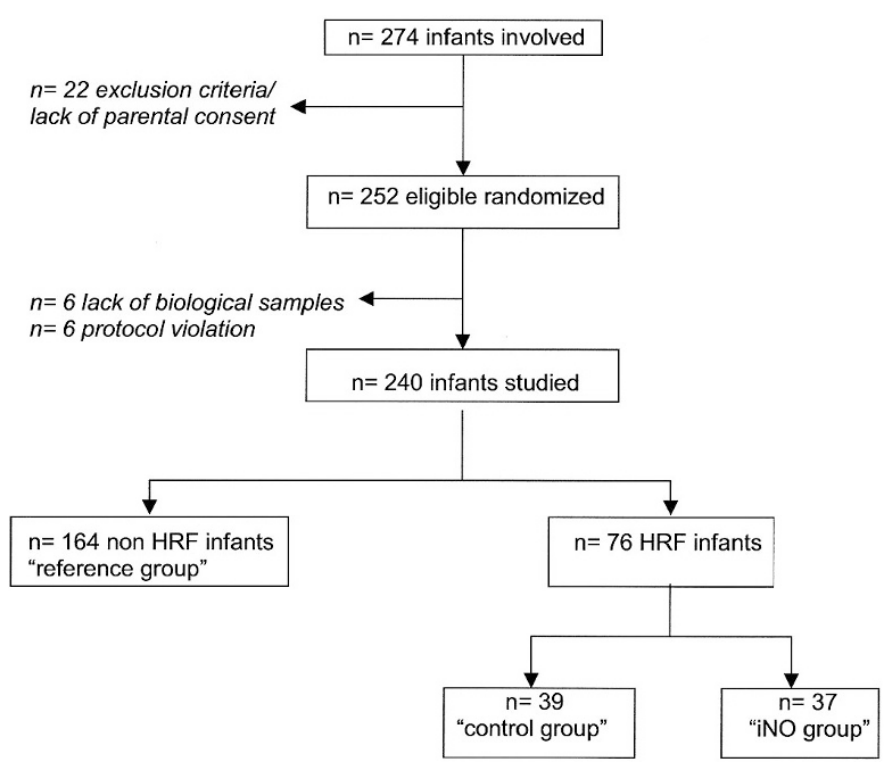

Figure 1. Trial profile. 
Table 1. Demographic and baseline characteristics of the infants

\begin{tabular}{|c|c|c|c|c|}
\hline Characteristics & $\begin{array}{c}\text { Reference } \\
{[n=164(\%)]}\end{array}$ & $\begin{array}{l}\text { Control-HRF } \\
{[n=39(\%)]}\end{array}$ & $\begin{array}{c}\text { iNO-HRF } \\
{[n=37(\%)]}\end{array}$ & $p$ value \\
\hline GA (wk) & $28.9 \pm 0.1$ & $27.9 \pm 0.4$ & $27.3 \pm 0.4$ & $<0.001 * \dagger$ \\
\hline Birth weight (g) & $1206 \pm 026$ & $1102 \pm 054$ & $1083 \pm 058$ & NS \\
\hline Antenatal steroids & $134(82)$ & $26(67)$ & $24(65)$ & $0.02 * \dagger$ \\
\hline Toxemia & $25(15)$ & $6(15)$ & $3(8)$ & NS \\
\hline Chorioamnionitis & $4(2)$ & $2(5)$ & $0(0)$ & NS \\
\hline Hyaline membrane disease & $97(59)$ & $39(100)$ & $35(94)$ & $<0.001 * \dagger$ \\
\hline \multicolumn{5}{|l|}{ CRIB score } \\
\hline$<6$ & $124(76)$ & $23(59)$ & $18(49)$ & $<0.01 * \dagger$ \\
\hline $5-10$ & $17(10)$ & $11(28)$ & $14(38)$ & \\
\hline$>10$ & $3(2)$ & $5(13)$ & $4(11)$ & \\
\hline
\end{tabular}

IUGR, intrauterine growth retardation.

$* p$ value significantly different between reference and control HRF.

$\dagger p$ value significantly different between reference and iNO HRF.

control and the iNO groups, whereas there was no difference within these two HRF groups (Table 1). The incidence of hyaline membrane disease was almost twice as much in both HRF groups than in the reference group. The incidence of poor postnatal adaptation assessed by the neonatal CRIB score (29) was higher in both HRF groups than in the reference group (Table 1). At the time of randomization, $\mathrm{FiO}_{2}$ requirement was significantly higher to start with in the iNO group than in the control group (Table 2).

Protocol. In our study, median duration of iNO administered according to the protocol was $35.1 \mathrm{~h}(21.7-53.9)$. There was no significant difference for the postnatal age at $T_{1}$ between the two hypoxemic groups $(14.1 \pm 1.4$ versus $15.9 \pm$ $1.8 \mathrm{~h}$ in controls, respectively). It was significantly higher, however, in the reference group $(29.4 \pm 0.8 \mathrm{~h} ; p<0.01)$. We verified within this group that there was no effect of time for the studied variables except a minimal effect on MDA (between 1 and $2 \%$ over $96 \mathrm{~h}$ ). Twenty-four hours after entering the randomization ( $T_{2}$ for biologic sampling), there was a significant drop in the $\mathrm{FIO}_{2}$ requirement in the iNO group $(-20.4 \pm 4.4$ versus $-7.4 \pm 3.7 \%$ for the controls; $p<0.01)$.

Biologic results. MDA. At the time of randomization $\left(\mathrm{T}_{1}\right)$, MDA levels were not significantly different among the three groups (Table 2). At $\mathrm{T}_{2}$, MDA increased moderately in the reference population $(1.63 \pm 0.79$; median, 1.4 [ -3.7 to 6.5$])$ as in the iNO HRF group [2.20 $\pm 2.57 ; 4.6$ ( -2.6 to 9.7)], whereas during this $24-\mathrm{h}$ period, HRF controls increased significantly their MDA level [12.11 $\pm 2.67 ; 8.4$ (4.4-20.6); $p<$ 0.05; Fig. 2A].

Total plasmatic GSH. At the time of randomization $\left(\mathrm{T}_{1}\right)$, GSH levels were not significantly different among the three groups (Table 2). At $\mathrm{T}_{2}$, GSH level decreased moderately in the reference population $[-0.025 \pm 0.014 ;-0.020(-0.080$ to $0.060)]$ in comparison with the iNO group $[-0.080 \pm 0.027$; $-0.055(-0.120$ to -0.010$)]$ and the HRF control $[-0.105 \pm$ $0.029 ;-0.070(-0.210$ to -0.000$)]$, where the drop reached statistical significance versus the reference group $(p<0.05$; Fig. 2B).

Table 2. Effect of early iNO on the $\mathrm{FIO}_{2}$ requirements and the oxidative balance in premature infants

\begin{tabular}{|c|c|c|c|}
\hline Parameters & Reference group & Control-HRF & iNO-HRF \\
\hline $\mathrm{FIO}_{2}$ at $\mathrm{T}_{1}(\%)$ & $\begin{array}{l}23.61 \pm 0.38^{* \dagger} \\
(n=164)\end{array}$ & $\begin{array}{l}51.97 \pm 3.08 * * \\
\quad(n=39)\end{array}$ & $\begin{array}{l}62.32 \pm 3.44 \dagger+ \\
\quad(n=37)\end{array}$ \\
\hline MDA at $T_{1}$ & $47.80 \pm 1.04 *$ & $41.80 \pm 1.92 *$ & $48.50 \pm 2.59$ \\
\hline GPX at $T_{1}$ & $10.86 \pm 0.22$ & $11.06 \pm 0.49$ & $11.07 \pm 0.38$ \\
\hline $\mathrm{GR}$ at $\mathrm{T}_{1}$ & $11.85 \pm 0.19$ & $11.61 \pm 0.40$ & $11.17 \pm 0.40$ \\
\hline$\Delta \mathrm{FIO}_{2}$ at $\mathrm{T}_{2}(\%)$ & $\begin{array}{c}-0.77 \pm 0.40 \dagger \\
(n=151)\end{array}$ & $\begin{array}{c}-7.36 \pm 3.72 \ddagger \\
(n=33)\end{array}$ & $\begin{array}{c}-20.42 \pm 4.42 \dagger \dagger \\
(n=36)\end{array}$ \\
\hline$\Delta \mathrm{GSH}$ at $\mathrm{T}_{2}$ & $\begin{array}{c}-0.025 \pm 0.014 * \\
(n=137)\end{array}$ & $\begin{array}{c}-0.105 \pm 0.029 * \\
(n=31)\end{array}$ & $\begin{array}{c}-0.08 \pm 0.027 \\
(n=34)\end{array}$ \\
\hline$\Delta \mathrm{GPX}$ at $\mathrm{T}_{2}$ & $\begin{array}{c}+0.06 \pm 0.12 \dagger \\
\quad(n=143)\end{array}$ & $\begin{array}{c}+0.36 \pm 0.21 \\
\quad(n=31)\end{array}$ & $\begin{array}{c}+0.90 \pm 0.25 \dagger \\
\quad(n=34)\end{array}$ \\
\hline$\Delta$ GR at $T_{2}$ & $\begin{array}{c}+0.58 \pm 0.13 \\
\quad(n=143)\end{array}$ & $\begin{array}{c}+0.48 \pm 0.41 \\
\quad(n=31)\end{array}$ & $\begin{array}{c}+0.81 \pm 0.31 \\
\quad(n=34)\end{array}$ \\
\hline
\end{tabular}

Results expressed as mean \pm SEM, $\Delta$ value $=\mathrm{T}_{2}-\mathrm{T}_{1}$.

$* p$ value significantly different $(p \leq 0.05)$ between reference and control HRF.

$\dagger p$ value significantly different between reference and iNO HRF and $\neq$ between control HRF and iNO HRF. 
A
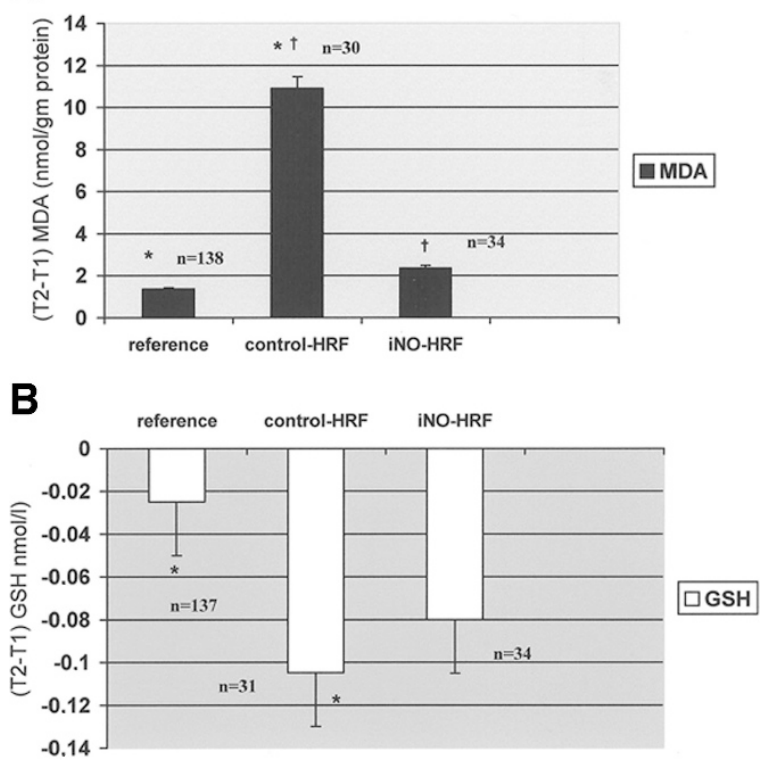

Figure 2. Oxidative stress balance over $24 \mathrm{~h}$ within the three groups of infants. (A) MDA changes. (B) Total plasmatic GSH changes. *p value significantly different $(<0.05)$ between "reference and control HRF" and $\dagger$ between "control HRF and iNO HRF". "n" = number of biological values.

Intraerythrocyte GPX activity. At the time of randomization $\left(\mathrm{T}_{1}\right)$, the GPX activity was not significantly different among the three groups. At $\mathrm{T}_{2}$, there was a significant increase $(p<0.05)$ in GPX activity for the iNO group $[0.90 \pm 0.25 ; 0.65(-0.10$ to 1.40)] in comparison with the reference group [0.06 \pm 0.12 ; $0.10(-0.40$ to 0.70$)]$, when the rise in GPX was not significantly different for the HRF controls [0.36 $\pm 0.21 ; 0.00$ ( -0.30 to 1.00$)]$.

Intraerythrocyte GR activity. At the time of randomization $\left(\mathrm{T}_{1}\right)$, the GR activity was not significantly different among the three groups. At $T_{2}$, the moderate rise in GR activity (Table 2) remained statistically not different among the three groups.

Clinical outcome on day 28. On day 28 of life, survival rate was $92 \%$ in the reference group versus $69 \%$ in the control group and 59\% in the iNO group. Fifty-five percent of the infants in the reference group versus $23 \%$ in the control group and $19 \%$ in the iNO group reached the primary measure of outcome ( $p<0.0001$ for the reference group versus the control and iNO groups, respectively), a composite value to describe "intact survival." The incidence of $\mathrm{O}_{2}$ dependence on day 28 was different among the three groups, with a significantly higher incidence for the HRF controls, when this incidence was not different between the reference population and the HRF infants who were treated with iNO (Table 3). The incidence of patent ductus arteriosus was significantly higher in both HRF groups in comparison with the reference group (Table 3). There was no statistical difference among the three groups for the incidence of IVH of any grade or the incidence of significant brain lesion (greater than IVH grade 1 and/or periventricular leukomalacia and/or hydrocephaly; Table 3).

Correlations between $\mathrm{F}_{\mathrm{IO}_{2}}$ changes and early oxidative stress. For MDA, the oxidative stress marker, we found a positive correlation with $\mathrm{FIO}_{2}$ requirements $(r=0.158, p=0.02)$. Moreover, MDA changes over $24 \mathrm{~h}\left(\mathrm{~T}_{2}-\mathrm{T}_{1}\right.$ values) were also correlated with $\mathrm{FiO}_{2}$ changes within the same period of time ( $r=$ $0.148, p=0.03$ ). For GSH, the antioxidant substrate, we found that the drop in GSH level over $24 \mathrm{~h}$ was correlated with the initial $\mathrm{FIO}_{2}$ requirements $(r=0.182, p=0.01)$.

Relationship between early oxidative stress and clinical outcome on day 28. We found no significant relationship between the early oxidative stress marker evaluated at $\mathrm{T}_{1}$ and the postnatal clinical outcome. However, MDA evolution, over a 24-h period $\left(\mathrm{T}_{2}-\mathrm{T}_{1}\right)$ was significantly associated with the risk for death, respiratory, and/or neurologic outcome on day 28.

For MDA, we found by univariate analysis that the magnitude of the early increase $\left(T_{2}-T_{1}\right)$ was significantly associated with the risk for death within the first $28 \mathrm{~d}$ of life $(p=$ 0.009 ), with the combined risk for death or having worrisome brain lesion $(p=0.004)$ or developing an oxygen dependence on D28 ( $p=0.003$; Table 4). For GSH, we found by univariate analysis that the magnitude of the early drop $\left(\mathrm{T}_{2}-\mathrm{T}_{1}\right)$ was significantly associated with the risk for developing a significant IVH ( $>$ grade I) during the first month of life $(p=0.03)$.

\section{DISCUSSION}

In our study, iNO was not associated with an increased oxidative stress in very preterm infants. On the contrary, we observed a significant improvement in the oxidative balance of very premature infants within the first days of life. Premature infants are highly susceptible to injury from reactive oxygen intermediates (ROI), and tissue injury occurs when ROI from endogenous and exogenous sources exceed the already limited antioxidant capacities $(17,30)$. Therefore, it seemed necessary to study the impact of iNO on both sides of the oxidative balance. Plasmatic MDA, a byproduct of cell membrane lipid

Table 3. Clinical outcome on day 28 of life among the three groups of infants

\begin{tabular}{|c|c|c|c|c|}
\hline Clinical outcome on day 28 & $\begin{array}{c}\text { Reference } \\
{[n=164(\%)]}\end{array}$ & $\begin{array}{l}\text { Control-HRF } \\
{[n=39(\%)]}\end{array}$ & $\begin{array}{c}\text { iNO-HRF } \\
{[n=37(\%)]}\end{array}$ & $p$ value \\
\hline Survival & $151(92.1)$ & $27(69.3)$ & $22(59.5)$ & $<0.001 * \dagger$ \\
\hline Oxygen dependence & $40(26.5)$ & $15(55.6)$ & $8(36.4)$ & $0.0099^{*}$ \\
\hline Cumulative incidence of IVH at last HUS examination (all grades) & $16(10.5)$ & $5(17.2)$ & $7(25.9)$ & 0.07 \\
\hline Significant brain lesion & $9(5.9)$ & $2(7.4)$ & $2(9.1)$ & NS \\
\hline Necrotizing enterocolitis & $31(18.9)$ & $4(10.2)$ & $4(10.8)$ & NS \\
\hline
\end{tabular}

PDA, patent ductus arteriosus; HUS, head ultrasound; "significant brain lesion," occurrence of any IVH > grade I and/or periventricular leukomalacia and/or hydrocephaly.

* $p$ value significantly different between reference and control HRF.

$\dagger p$ value significantly different between reference and iNO. 
Table 4. Relationship between the initial oxidative stress and the clinical outcome of the infants on day 28

\begin{tabular}{|c|c|c|c|c|}
\hline $\begin{array}{l}\text { Clinical outcome on } \\
\text { day } 28 \text { of life }\end{array}$ & $\begin{array}{l}\text { No. of infants } \\
\text { evaluated }\end{array}$ & $\begin{array}{c}\Delta(\mathrm{T} 2-\mathrm{T} 1) \mathrm{MDA} \\
(\text { mean } \pm \mathrm{SEM})\end{array}$ & $p$ value & $\begin{array}{c}\text { OR } \Delta \text { MDA } \\
(95 \% \mathrm{CI})\end{array}$ \\
\hline \multicolumn{5}{|l|}{ Death } \\
\hline No & 169 & $+2.42 \pm 0.74$ & 0.009 & 1.23 \\
\hline \multicolumn{5}{|l|}{ Death + total neuro } \\
\hline No & 156 & $+2.20 \pm 0.75$ & 0.004 & 1.21 \\
\hline Yes & 46 & $+6.91 \pm 2.60$ & & $(1.04-1.39)$ \\
\hline \multirow[t]{2}{*}{ Yes } & 60 & $+4.99 \pm 1.11$ & & $(1.04-1.47)$ \\
\hline & & $\begin{array}{c}\Delta(\mathrm{T} 2-\mathrm{T} 1) \mathrm{GSH} \\
(\text { mean } \pm \mathrm{SEM})\end{array}$ & & $\begin{array}{c}\text { OR } \Delta \mathrm{GSH} \\
(95 \% \mathrm{CI})\end{array}$ \\
\hline \multicolumn{5}{|l|}{ Any $\mathrm{IVH}>$ grade $\mathrm{I}$} \\
\hline No & 153 & $-0.038 \pm 0.011$ & 0.03 & 0.045 \\
\hline
\end{tabular}

OR, odds ratio; CI, confidence interval; Death + total neuro on day 28 death and/or neurologic permanent abnormality at HUS examinations (HIV $>$ grade I and/or periventricular leukomalacia and/or hydrocephaly).

$p<0.05$ : significant association between the clinical risk on day 28 death, death and/or neurologic abnormality, $\mathrm{O}_{2}$ dependence, or IVH and $\Delta$ (T2-T1) evolution of biological markers of oxidative stress.

peroxidation as a result of ROI, has been accepted as a valid indicator of oxidative stress in the neonate $(31,32)$. In our study, we were able to demonstrate a direct link between the levels of oxygen exposure and the magnitude of MDA rise in very premature infants. iNO led to a significant decrease in early $\mathrm{FiO}_{2}$ requirements, and the MDA levels of the HRF infants who were treated with iNO were not significantly different from the reference population after $24 \mathrm{~h}$, when those of the HRF controls were significantly rising. However, the number of HRF infants was too small to show a direct impact of iNO on MDA levels, and we can only speculate that MDA level stabilization was obtained thanks to the important drop in $\mathrm{FiO}_{2}$ requirement $(-20 \%$ over $24 \mathrm{~h}$ ). A rapid improvement in oxygenation after iNO in premature infants is described in several studies $(7,14)$, but the originality of our prospective controlled study was to obtain this response with very low doses $(\leq 5 \mathrm{ppm})(33)$ over a short period of time, when others were using from 5 (11), to 10 (6), and often $20 \mathrm{ppm}$ $(7,8,10)$.

On the other side of the oxidative stress balance, we chose total plasmatic GSH as a biologic marker of the antioxidant defense pool, able to detoxify hydrogen peroxide and other peroxides in a reaction catalyzed by GPX. GR is the main enzyme able to restore intracellular GSH levels. Several clinical data have shown that plasmatic GSH concentrations are low in premature infants and inversely proportional to GA $(34,35)$. A further early depletion as a result of the adjunction of a new oxidant molecule would be worrisome. With the clinical settings of our study, the sick infants who were treated with low-dose iNO had a trend toward a less severe depletion in GSH levels than the sick control subjects and were not significantly different from the reference group. Because NO does not have any direct impact on the GSH metabolism, we can speculate that $\mathrm{iNO}$, by reducing early $\mathrm{FiO}_{2}$ requirements and ROI, indirectly decreases the need for scavenger use. Thus, by reducing the magnitude of both oxidant production and antioxidant depletion, iNO that is administered early in the postnatal course $(14-16 \mathrm{~h}$ of life $)$ and at a small dosage $(\leq 5$ $\mathrm{ppm}$ ) in hypoxemic premature infants seems to be able to blunt the oxidative cascade triggered by high initial oxygen concentrations.

Because this study was an ancillary part of a larger, prospective, safety-efficacy controlled trial of early iNO in hypoxemic very premature infants (22), we were able to benefit from the collection of all postnatal data of these infants. This gave us clues to answer the yet unsolved question $(30,35)$ : does the biologic stabilization of the early oxidative stress have any sustained clinical benefits in this high-risk population? On day 28 of life, when most of these infants have reached a stable clinical condition and the inflammatory processes triggered by oxidative stress has been identified, we found a significant relationship between clinical outcome and early oxidative balance. The early increase of MDA plasmatic levels was significantly associated with the risk for death during the first month of life $(\mathrm{OR}=1.23)$ as well as the risk for death and/or severe neurologic abnormalities $(\mathrm{OR}=1.21)$. The significant relationship between early MDA increase and the risk for having an oxygen dependence on day $28(\mathrm{OR}=1.24)$ is consistent with previous publications $(30,31,36-39)$. Data indicating that early lipid peroxidation occurs in infants who subsequently develop bronchopulmonary dysplasia (BPD) came from Pitkanen et al. (37) in 1990. They also demonstrated that increased concentration of exhaled pentane and ethane occurred early and at higher levels in preterm than in term infants, indicating a higher oxidative stress in the former group $(37,38)$. Inder et al. (31) found a positive correlation between lipid peroxidation measured by MDA-thiobarbituric acid in 22 very low birth weight infants and the number of days with high $\mathrm{FIO}_{2}$ levels. MDA-thiobarbituric acid values were $~ 50 \%$ higher in the infants who developed BPD (31). Ogihara et al. (32) also found a positive correlation between an elevated level of several aldehydes, products of lipid peroxidation in 13 preterm infants, on the first day of life, and the risk for BPD. At 4-6 $\mathrm{d}$ of life, no more significant correlation was found, suggesting 
that early oxidative stress has a stronger impact on subsequent clinical outcome (32). Finally, Weinberger et al. (40), in a study on 25 premature infants, confirmed that elevated urinary MDA in the first days of life was correlated with a risk for oxygen radical disease.

For the antioxidant defenses, we found a link between the magnitude of early depletion in plasmatic GSH and the risk for developing IVH within the first $28 \mathrm{~d}$ of life $(\mathrm{OR}=0.045)$. To our knowledge, this is the first time such a relation has been established in very premature infants. Most of the studies focused on the impact of low antioxidant defenses on the incidence of BPD. Neonates are short in antioxidant defenses, on both their extracellular $(41,42)$ and intracellular part $(42,43)$. Moreover, in preterm animals, in contrast with term, induction of antioxidative enzymes does not occur after oxidative stress $(41,44)$. Randomized trials of antioxidant intervention in premature infants, with strong rationale and good study design, failed to demonstrate any improvement on BPD incidence $(36,45-47)$. In our study, we speculate that low-dose iNO probably did not act as an antioxidant by itself but by reducing the oxidative stress as a result of high oxygen concentration allowed a less dramatic consumption of GSH stores.

NO is a free radical that may be oxidized or reduced depending on its concentration and the presence of other oxidants such as oxygen. Hyperoxic exposure of rat pups up-regulates both inducible and endothelial NO synthase and therefore increases the concentration of NO and subsequently peroxynitrite as well (48). This compound is highly toxic for preterm infants. Reports regarding the effect of NO in oxidative stress, however, are conflicting (43). In experimental studies, several authors found a worse clinical outcome or surfactant dysfunction as a result of lipid peroxidation or damage to surfactant protein, but they often used very high doses of NO (40-100 ppm) combined with high and stable $\mathrm{FIO}_{2}$ levels $(80-100 \%)(19,43,49)$. Because of these data, wide use of iNO therapy in preterm infants is unwarranted by most neonatologists $(13-15,50)$.

In our study, we continuously monitored by transcutaneous $\mathrm{PaO}_{2}$ the infants' response to iNO, and we aimed to wean both iNO and oxygen as quickly as possible keeping $\mathrm{PaO}_{2}$ between 50 and $65 \mathrm{~mm} \mathrm{Hg}$. Because of the continuous monitoring of iNO (to ensure constant dosage) and of $\mathrm{NO}_{2}$ (to verify safety), it was difficult to blind the administration of the gas with the design of this study. However, the duration of treatment was short ( $35 \mathrm{~h}$ on average), the infants were treated following standardized written protocol, and the clinicians in charge of the infants on day 28 were not aware of the allocation. In addition, randomization remained blinded for biologic analysis as well as for head ultrasound examination. Therefore, a bias related to unmasked administration of $\mathrm{NO}$ on biologic data or neurologic outcome is unlikely. Our strategy of treatment of lowering $\mathrm{FIO}_{2}$ as soon as possible by continuous follow-up of $\mathrm{PaO}_{2}$ may explain the positive results on the oxidative stress balance as well as on clinical outcome, in comparison with experimental models using the combined and toxic combination of high iNO and $\mathrm{FIO}_{2}$ levels without any decrease according to the animal response $(48,49)$. In addition, experimental data suggest that iNO might have direct antioxidant properties reducing the inflammatory reaction in the lungs (51). Kinsella et al. (11) were the first to use $5 \mathrm{ppm}$ of iNO in a prospective trial on 80 very sick premature infants who were $\leq 32$ wk for at least $7 \mathrm{~d}$. They showed, besides an early positive response on oxygenation, no change in the mortality rate but a significant decrease in the need for mechanical ventilation and the incidence of chronic lung disease. Many studies that have evaluated the effect of iNO in premature infants at an advanced stage of respiratory failure (12) failed to demonstrate an effect on mortality and/or outcome (8-11). In those studies, all infants did not respond to iNO, whereas the outcome was improved in the responders (22). Noteworthy, the first study to demonstrate a positive effect of iNO has treated infants early, with a low severity of respiratory disease (52). In this study, Schreiber et al. (52) used $10 \mathrm{ppm}$ of iNO in 105 infants who were $<34 \mathrm{wk}$ and compared the incidence of chronic lung disease or death with 102 control subjects. They found a positive effect of iNO despite the low severity of initial HRF disease assessed by a mean oxygenation index of 6.8. In our study, we considered iNO therapy only in infants who required $>40 \% \quad \mathrm{FIO}_{2}$ and enrolled $76 \mathrm{HRF}$ infants among whom the infants randomly assigned to receive iNO $(n=37)$ were slightly sicker to start with than control subjects (Table 1). Despite these worse initial conditions, this subgroup was able to respond to low-dose iNO, to decrease its early oxidative stress, and to have a relatively fair clinical outcome in comparison with most of the other studies $(14,52)$. Therefore, one could speculate that the lack of significant results on the outcome in most of the studies with iNO might be related to the policy of treatment used in these studies.

\section{CONCLUSION}

Our study demonstrates that low doses of iNO administered soon after birth in very preterm infants who have moderate hypoxemic respiratory failure is associated with a decrease in their oxidative stress. We speculate that this impact of iNO occurs thanks to an early, rapid, and sustained decrease in $\mathrm{FIO}_{2}$ requirements, at a postnatal age when the deleterious cascade of oxidative/inflammatory injuries can be reversed.

Acknowledgments. We are indebted to Prof. Pierre Nabet for providing us with the skills and generous access to his laboratory, and we also thank Dr. Brigitte Dousset and Dr. Henri Schroeder for precious advice.

\section{REFERENCES}

1. Kinsella JP, Neish S, Shaffer E, Abman SH 1992 Low dose inhalation nitric oxide in persistent pulmonary hypertension of the newborn. Lancet 340:819-820

2. NINOS (The Neonatal Inhaled Nitric Oxide Study Group) 1997 Inhaled nitric oxide in full-term and nearly full-term infants with hypoxic respiratory failure. N Engl J Med 336:597-604

3. Kinsella JP, Truog WE, Walsh WF, Goldberg RN, Bancalari E, Mayock DE, Redding GJ, deLemos RA, Sardesai S, McCurnin D, Moreland SG, Cutter GR, Abman SH 1997 Randomized, muticenter trial of inhaled nitric oxide and high-frequency oscillatory ventilation in severe, persistent pulmonary hypertension of the newborn. J Pediatr 131:55-62

4. Davidson D, Barefield ES, Kattwinkel J, Dudell G, Damask M, Straube R, Rhines J, Chang CT 1998 Inhaled nitric oxide for the early treatment of persistent pulmonary hypertension of the term newborn: a randomized, double-masked, placebo-controlled, dose-response, multicenter study. The I-NO/PPHN Study Group. Pediatrics 101:325334 
5. Finer NN, Barrington KJ 2000 Nitric oxide for respiratory failure in infants born at or near term. Cochrane Database Syst Rev (2):CD000399

6. Franco-Belgium Collaborative NO Trial Group 1999 Early compared with delayed inhaled nitric oxide in moderately hypoxaemic neonates with respiratory failure: a randomised controlled trial. Lancet 354:1066-1071

7. Skimming JW, Bender KA, Hutchinson AA, Drummond WH 1997 Nitric oxide inhalation in infants with respiratory distress syndrome. J Pediatr 130:225-230

8. Peliowski A, Finer NN, Etches PC, Tierney AJ, Ryan CA 1995 Inhaled nitric oxide for premature infants after prolonged rupture of the membranes. J Pediatr 126:450453

9. Subhedar NV, Ryan SW, Shaw NJ 1997 Open randomised controlled trial of inhaled nitric oxide and early dexamethasone in high risk preterm infants. Arch Dis Child Fetal Neonatal Ed 77:F185-F190

10. Meurs KP, Rhine J, Asselin JM, Durand DJ 1997 Response of premature infants with severe respiratory failure to inhaled nitric oxide. Preemie NO Collaborative Group. Pediatr Pulmonol 24:319-323

11. Kinsella JP, Walsh WF, Bose CL, Gerstmann DR, Labella JJ, Sardesai S, WalshSukys MC, Mc Caffey MJ, Cornfield DN, Bhutani VK, Cutter GR, Baier M, Abman SH 1999 Inhaled nitric oxide in premature neonates with severe hypoxemic respiratory failure: a randomised controlled trial. Lancet 354:1061-1065

12. Banks BA, Seri I, Ischiropoulos H, Merrill J, Rychick J, Ballard RA 1999 Change in oxygenation with inhaled nitric oxide in severe bronchopulmonary dysplasia. Pediatrics 103:610-618

13. Bland RD 1999 Inhaled nitric oxide: a premature remedy for chronic lung disease. Pediatrics 103:667-670

14. Hoehn T, Krause MF 2001 Response to inhaled nitric oxide in premature and term neonates. Drugs 61:27-39

15. Mercier JC, Franco-Belgium Neonatal Study Group on Inhaled NO 2001 Uncertainties about the use of nitric oxide in preterm infants. Acta Paediatr Suppl 90:15-18

16. Cheung PY, Salas E, Etches PC, Phillipos E, Shultz R, Randomski MW 1998 Inhaled nitric oxide and inhibition of platelet aggregation in critically ill neonates. Lance $351: 1181-1182$

17. Saugstad OD 1996 Mechanisms of tissue injury by oxygen radicals; implications for neonatal disease. Acta Paediatr 85:1-4

18. Haddad IY, Ischiropoulos H, Holm BA, Beckman JS, Baker JR, Matalon S 1993 Mechanisms of peroxynitrite-induced injury to pulmonary surfactants. Am J Physiol 265:L555-L564

19. Hallman M, Waffarn F, Bry K, Turbow R, Kleinman MT, Montz WJ, Rasmussen RE, Bhalla DK, Phalen RF 1996 Surfactant dysfunction after inhalation of nitric oxide. J Appl Physiol 80:2026-2034

20. Issa A, Lappalainen U, Kleinman M, Bry K, Hallman M 1999 Inhaled nitric oxide decreases hyperoxia-induced surfactant abnormality in preterm rabbits. Pediatr Res 45:247-254

21. Hallman M 1997 Molecular interactions between nitric oxide and lung surfactant Biol Neonate 71:44-48

22. Hascoet JM, Fresson J, Claris O, Hamon I, Lombet J, Liska A, Cantagrel S, Al Hosri J, Thiriez G, Valdes V, Vittu G, Egreteau L, Henrot A, Buchweiller M-C, Onody P 2005 The safety and efficacy of nitric oxide therapy in very preterm infants. J Pediatr 146:318-323

23. Yagi K 1976 A simple fluorometric assay for lipoperoxide in blood plasma. Biochem Res 15:212-216

24. Wong SH, Knight JA, Hopfer SM, Zaharia O, Leach CN Jr, Sunderman FW Jr 1987 Lipoperoxides in plasma as measured by liquid-chromatographic separation of malondialdehyde-thiobarbituric acid adduct. Clin Chem 33:214-220

25. Coutelle C, Iron A, Higueret D, Cassaigne A 1992 Optimization of a spectrophotometry assay of total and oxidized blood glutathione: comparison with a fluorimetric method. Ann Biol Clin (Paris) 50:71-76

26. Paglia DE, Valantine WN 1967 Studies on the quantitative and qualitative characterization of erythrocyte glutathione peroxidase. J Lab Clin Med 70:158-169

27. Goldberg DM, Spooner RJ (1983) Dosage of erythrocyte glutathione reductase, in Methods of Enzymatic Analysis (Bergmeyer J, Grassl M eds), 3rd ed, pp 258-265. Verlag Chemie, Deerfield Beach, FL.

28. Papile LA, Burstein J, Burstein R, Koffler H 1978 Incidence and evolution of subependymal and intraventricular hemorrhage: a study of infants with birthweight less than 1,500 gm. J Pediatr 92:529-534
29. Egreteau L, Pauchard JY, Semama DS, Matis J, Liska A, Romeo B, Cneude F, Hamon I, Truffert P 2001 Chronic oxygen dependency in infants born at less than 32 weeks' gestation: incidence and risk factors. Pediatrics 108:E26

30. Saugstad OD 2001 Update on oxygen radical disease in neonatology. Curr Opin Obstet Gynecol 13:147-153

31. Inder TE, Graham P, Sanderson K, Taylor BJ 1994 Lipid peroxidation as a measure of oxygen free radical damage in the very low birth weight infant. Arch Dis Child Fetal Neonatal Ed 70:F107-F111

32. Ogihara T, Hirano K, Morinobu T, Kim HS, Hiroi M, Ogihara H, Tamai H 1999 Raised concentrations of aldehyde lipid peroxidation products in premature infants with chronic lung disease. Arch Dis Child Fetal Neonatal Ed 80:F21-F25

33. Desandes R, Desandes E, Droullé P, Didier F, Longrois D, Hascoet JM 2004 Inhaled nitric oxide improves oxygenation in very premature infants with low pulmonary blood flow. Acta Paediatr 93:66-69

34. Abman SH 2002 Monitoring cardiovascular function in infants with chronic lung disease of the prematurity. Arch Dis Child Fetal Neonatal Ed 87:F15-F18

35. Jain A, Mehta T, Auld PA, Rodrigues J, Ward RF, Schwartz MK, Martensson J 1995 Glutathione metabolism in newborns: evidence for glutathione deficiency in plasma, bronchoalveolar lavage fluid, and lymphocytes in prematures. Pediatr Pulmonol 20:160-166

36. Welty SE 2003 Antioxidants and oxidations in bronchopulmonary dysplasia: there are no easy answers. J Pediatr 143:697-698

37. Pitkanen OM, Hallman M, Andersson S 1990 Correlation of free oxygen radicalinduced lipid peroxidation with outcome in the very low birth weight infants. J Pediat 116:760-764

38. Varsila E, Hallman M, Andersson S 1994 Free-radical-induced lipid peroxidation during the early neonatal period. Acta Paediatr 83:692-695

39. Varsila E, Pitkanen OM, Hallman M, Andersson S 1994 Immaturity-dependent free radical activity in premature infants. Pediatr Res 36:55-59

40. Weinberger B, Anwar M, Henien S, Sosnovsky A, Hiatt M, Jochnowitz N, Witz G, Hegyi T 2004 Association of lipid peroxidation with antenatal betamethasone and oxygen radical disorders in preterm infants. Biol Neonate 85:121-127

41. Berger HM, Molicki JS, Moison RM, Van Zoeren-Grobben D 1998 Extracellular defence against oxidative stress in the newborn. Semin Neonatol 3:183-190

42. Frank L 1998 Development of the antioxidant defences in fetal life. Semin Neonatol $3: 173-182$

43. Saugstad OD 2003 Bronchopulmonary dysplasia-oxidative stress and antioxidants Semin Neonatol 8:39-49

44. Frank L, Sosenko IR 1991 Failure of premature rabbits to increase antioxidan enzymes during hyperoxic exposure: increased susceptibility to pulmonary oxygen toxicity compared to term rabbits. Pediatr Res 29:292-296

45. Ahola T, Lapatto R, Raivio KL, Selander B, Stigson L, Jonsson B, Jonsbo F, Esber G, Stovring S, Kjartansson S, Stiris T, Lossius K, Virkola K, Fellman V 2003 $\mathrm{N}$-acetylcysteine does not prevent bronchopulmonary dysplasia in immature infants: a randomized controlled trial. J Pediatr 143:713-719

46. Davis JM, Parad RB, Michele T, Allred E, Price A, Rosenfeld W; North American Recombinant Human CuZnSOD Study Group 2003 Pulmonary outcome at 1 year corrected age in premature infants treated at birth with recombinant $\mathrm{CuZn}$ superoxide dismutase. Pediatrics 111:469-476

47. Russell GA, Cooke RW 1995 Randomised controlled trial of allopurinol prophylaxis in very preterm infants. Arch Dis Child Fetal Neonatal Ed 73:F27-F3

48. Potter CF, Kuo NT, Farver CF, McMahon JT, Chang CH, Agani FH, Haxhiu MA, Martin RJ 1999 Effects of hyperoxia on nitric oxide synthase expression, nitric oxide activity, and lung injury in rat pups. Pediatr Res 45:8-13

49. Robbins CG, Davis JM, Merritt TA, Amirkhanian JD, Sahgal N, Morin FC 3rd, Horowitz S 1995 Combined effects of nitric oxide and hyperoxia on surfactant function and pulmonary inflammation. Am J Physiol 269:L545-L550

50. Saugstad OD 1999 Inhaled nitric oxide for preterm infants-still en experimental therapy. Lancet 354:1047-1048

51. Kinsella JP, Parker TA, Galan H, Sheridan BC, Halbower AC, Abman SH 1997 Effects of inhaled nitric oxide on pulmonary edema and lung neutrophil accumulation in severe experimental hyaline membrane disease. Pediatr Res 41:457-463

52. Schreiber MD, Gin-Mestan K, Marks JD, Huo D, Lee G, Srisuparp P 2003 Inhaled nitric oxide in premature infants with respiratory distress syndrome. N Engl J Med 349:2099-2107 